\title{
Training of Contracted Family Physicians in Turkey
}

\author{
Türkiye'de Sözleşmeli Aile Hekimliği Uzmanlık Eğitimi \\ Sinan Bulut
}

\section{ÖZET}

Sözleşmeli Aile Hekimliği Uzmanlık Eğitimi, Sağlık Bakanlığı tarafından aile hekimliği hizmetlerinin aile hekimliği uzmanlarınca verilmesini sağlamak ve bu kapsamda uzman sayısını artırmak amacıyla, sözleşmeli olarak aile hekimliği yapan hekimlere yönelik 2014 yılı itibarı ile başlatılmıştır. 2014 yılı ilkbahar dönemi yerleştirmesi ile başlayan ve 2020 yılına kadar devam etmesi planlanan eğitimde, birtakım temel sorunlar ile karşılaşılmıştır. Bu sorunların başında, aile hekimlerince eğitime olan talebin düşüklüğ̈̈ ve eğitimin yaygınlaştırılamaması gelmektedir. Eğitime yönelik bu temel sorunların ve karşılaşılan diğer problemlerin çözümünde Sağlık Bakanlığı ve Türkiye Halk Sağlığı Kurumunun attığı adımların yanı sıra aile hekimliği anabilim dallarının katkıları da belirleyici olacaktır.

Anahtar kelimeler: Aile hekimliği, uzmanlık eğitimi, birinci basamak sağlık hizmetleri, aile hekimi

\begin{abstract}
Training of Contracted Family Physicians was initiated in 2014 by the Ministry of Health intended for family doctors in order to ensure that the family medicine services are provided by the family medicine specialists and to increase the number of experts in this scope. During the training which started with job placement in the spring of 2014 and was planned to continue until 2020, some basic problems were encountered. The most common problems are the low demand for education by family physicians, and the inability to disseminate education. In addition to the steps taken by the Ministry of Health and Public Health Institution of Turkey in solving these basic education problems and other problems, the contribution of family medicine education branches will also be decisive.
\end{abstract}

Keywords: Family medicine, specialist training, primary health care, family physician

Received / Geliş tarihi: 21.10.2016, Accepted / Kabul tarihi: 16.02 .2017

Türkiye Halk Sağlığı Kurumu Aile Hekimliği Eğitim ve Geliştirme Daire Başkanlığ 1

*Address for Correspondence / Yazışma Adresi: Sinan Bulut, Türkiye Halk Sağlığı Kurumu Aile Hekimliği Eğitim ve Geliştirme Daire Başkanlığı, Ankara- TÜRKIYE, E-mail: Sinan.062@ @otmail.com

Bulut S. Türkiye'de Sözleşmeli Aile Hekimliği Uzmanlık Eğitimi, TJFMPC, 2017;11(2): 67-70.

DOI: $10.21763 /$ tjfmpc.317707 


\section{Sayın Editör,}

Yıldız Yardımcı ve arkadaşları tarafından imzalı Turkish Journal of Family Medicine and Primary Care Dergisi'nin 2016 yıl1, (10)2 say1 81-90 sayfalarında yer alan “Türkiye'de Aile Hekimliği Uygulaması ve Sözleşmeli Aile Hekimliği Uzmanlık Eğitimi” isimli derlemeyi okudum. Söz konusu derlemenin Sözleşmeli Aile Hekimliği Uzmanlık Eğitimi (SAHU) bölümüne ilişkin katkılarımı sunmak isterim.

Öncelikle Türkiye'de aile hekimliği uzmanlık eğitimine yönelik 2014 yllı ilkbahar döneminde başlamış ve 2016 ilkbahar dönemi yerleştirmesi ile devam eden SAHU eğitimine yönelik bilgilendirici bir değerlendirmenin yayınlanmasını, bu eğitimin değerlendirilmesine önemli katkıları olacağı sebebiyle değerli gördüğümü ifade etmek isterim.

Yayınlanan makalede SAHU eğitimine yönelik yer alan değerlendirmeleri okuduktan sonra eğitimle ilgili belirtilen birçok hususa katılmakla birlikte, SAHU eğitiminde önemli bir belirleyici olan aile hekimliği akademisyenlerinin tutumlarına da değinilmesinin yararlı olacağı kanısındayım.

Eğitim süreçlerinin en önemli paydaşları olan öğrenciler karşılaştıkları vakalarda deneyimli klinisyenlerden kendilerine rehberlik etmelerini beklerler. Anabilim dalında görev yapan klinisyenlerinin sahada görev yapan hekimlerin deneyimlerinden yararlanmaları da anabilim dallarının faaliyetlerinin tam olarak yerine getirilmesine yardımc olmaktadır. ${ }^{1} \mathrm{Bu}$ kapsamda aile hekimliği uygulamalarının, birinci basamak odaklı kendine özgü eğitim içeriği, araştırması, kanıt temeli ve klinik uygulaması olan aile hekimliği disiplinin kılavuzluğu olmadan geliştirilmesi güçleşmektedir. Uygulamaların geliştirilmesine yönelik çözümün temelinde kuramsal ve uygulama düzeylerinde akademi ile sahanın bütünleşmesinin sağlanması gerekmektedir. $^{2}$

SAHU eğitimi, aile hekimliği hizmetinin aile hekimliği uzmanlarınca sunulmasını ve hizmet sunum kalitesinin artmasını sağlamak amacıyla; sahada çalışmakta olan aile hekimlerine yönelik olarak düzenlenen bir eğitimdir. Bu eğitimle, birinci basamakta sağlık hizmetinin uzman hekimlerce verilmesi ile sağlık sorunlarının önemli ölçüde birinci basamakta çözülerek, ikinci ve üçüncü basamağa başvurunun azaltılması da amaçlanmıştır. SAHU eğitiminde kontenjan planlaması aşaması, Tıpta Uzmanlık Kurulu tarafından yıllık global ülke kontenjanın belirlenmesi sonrasında Türkiye Halk Sağlığı Kurumu (THSK) tarafından, eğitim kurumlarına gönderilen kontenjan talep formu ile eğitim kurumlarından ilgili döneme ait kontenjan taleplerinin istenmesi ile başlamakta ve eğitim kurumları tarafindan talep edilen kontenjanların yerleştirme işlemleri için ilan edilmesi ile devam edilmektedir. ${ }^{3}$ THSK tarafından yürütülen SAHU yerleştirmeleri 01.01.2020 tarihine kadar devam edecektir.

Yazarlar tarafindan SAHU eğitiminin, talebin azlığı, kontenjan sayısının giderek azalması, aile hekimliği uzmanlık eğitimi ile çelişkileri gibi sebeplerle başarılı olamadığı ve 2020 yılına kadar da bu eğitimi tamamlayan hekim sayısının çok fazla olmayacağı değerlendirilmiştir.

SAHU eğitiminin geliştirilmesi gereken ve eksik yönleri olarak belirtilen bu hususların yanı sıra, kanaatimce bir diğer husus da, SAHU eğitimine birçok eğitim kurumu aile hekimliği anabilim dallarının, gerek kontenjan bildirimleri gerekse de eğitimin geliştirilmesi yönünden yeterince destek verememesidir. Nitekim birçok aile hekimliği akademisyeni, SAHU eğitiminin gerekli ve yeterli bir uzmanlık eğitimi olmadığı, mevcut 3 yıllık aile hekimliği uzmanlık eğitimini olumsuz etkileyeceği değerlendirmesiyle, eğitimin başlangıç yılı olan 2014'de, SAHU eğitiminin olmaması gerektiği yönünde görüşlerini açıklamışlardır. ${ }^{4}$

Yazarlarca da belirtildiği gibi, SAHU eğitiminin en önemli kısıtlılığı ve belki de eğitimin geleceğini belirleyen en önemli unsur, aile hekiminin görev yaptığı ilde açılan kontenjan dışında başka bir ilde eğitim alamaması olarak ifade edilebilir. Bu durum diğer illerde bu eğitime dâhil olmak isteyip de, olamayan pek çok hekimin eğitimden mahrum kalmasına sebep olmaktadır. İki bin on altı yılı sonbahar dönemine kadar, SAHU eğitiminde açılan kontenjanların il dağılımına baktığımızda (Tablo 1) en fazla il çeşitliliği 2014 yılı sonbahar döneminde 14 il ile sınırlı kalmıştır. $5,6,7,8,9,10$

Kontenjan sınırlılığının aşılması ve eğitimin en büyük eksikliği olan, ülke geneline yaygınlaştırılamaması sorununun, kontenjanların illere yaygınlaştırılması ile aşılacağı aşikârdır. Kontenjanların ülke geneline yayılmasında da, aile hekimliği anabilim dallarına büyük görev düşmektedir. Her ne kadar bazı eğitim kurumlarında eğitici olmasa da, Türkiye genelinde aile hekimliği anabilim dalı bulunan üniversite ve eğitim araştırma hastanelerince kontenjan talebinin yapılması durumunda eğitimin ülke geneline yayılabileceği ve eğitim kurumu bulunmayan illerdeki hekimlerin de en yakın ilde SAHU eğitimine dâhil edilmesi ile yapılacak planlama bu sorunun çözümü olabilecektir. Ayrıca, SAHU eğitiminin ülke geneline yayılması ile eğitim daha 
erişilebilir olacak ve gelecek yıllarda aile hekimliği

uzman sayısında da artış oluşturacaktır.

\begin{tabular}{|l|l|l|l|l|l|}
\hline \multicolumn{2}{|c|}{ Tablo 1. Yerleştirme dönemlerine göre SAHU kontenjanı açılan iller } \\
\hline İlkbahar & Sonbahar & \multicolumn{3}{c|}{$\mathbf{2 0 1 5}$} & \multicolumn{2}{c|}{$\mathbf{2 0 1 6}$} \\
\hline Adana & Idkbahar & Sonbahar & İlkbahar & Sonbahar \\
\hline Ankara & Ankara & Adana & Adana & Adana & Ankara \\
\hline Antalya & Antalya & Ankara & Ankara & Ankara & Çorum \\
\hline Bursa & Bursa & Bursa & Rize & Bursa & Kocaeli \\
\hline İstanbul & Edirne & İstanbul & Sakarya & İstanbul & Sakarya \\
\hline İzmir & İstanbul & İzmir & & İzmir & Samsun \\
\hline Kocaeli & İzmir & Konya & & Sakarya & \\
\hline Konya & Karabük & Sakarya & & & \\
\hline Samsun & Kocaeli & Edirne & & & \\
\hline Rize & Konya & Samsun & & & \\
\hline Sakarya & Rize & Malatya & & & \\
\hline & Sakarya & & & & \\
\hline & Samsun & & & & \\
\hline & Yozgat & & & & \\
\hline
\end{tabular}

SAHU eğitimi ile aile hekimliği uzmanı sayısında artış sağlanabileceği gibi, birinci basamak hizmet kalitesinde de gelişme sağlanacaktır. SAHU eğitimi, aile hekimliği yapan pratisyen hekimlerin, doğrudan karşılaştıkları vakaları, sorunlarını, çözüm önerilerini akademik ortamlara taşımalarına, teorik ve pratik açıdan eksiklerini akademisyenler ile karşılıklı bilgi ve deneyim alışverişi ile gidermelerine olanak sağlamaktadır. $\mathrm{Bu}$ kapsamda SAHU eğitiminin, sahadaki hizmet sunumunun kalitesini olumlu yönde etkileyeceği değerlendirilmekle birlikte, akademisyenlerin de SAHU öğrencileri vasitasıyla aile hekimliği hizmetlerinin kalitesine müdahil olabileceği göz önünde bulundurulmalıdır.

Sonuç olarak, Türkiye'de birinci basamak hizmetlerinin uzman hekim eli ile verilmesi ve aile hekimliği uzman sayısının arttırılması için önemli bir firsat olarak düşünülebilecek SAHU eğitiminde, Sağlık Bakanlığı ve THSK'nın uygulamaları eşliğinde eğitim kurumları anabilim dalı akademisyenlerinin desteğinin de kaçınılmaz olduğu görülmektedir.

Saygilarımla. 


\section{KAYNAKLAR}

1. Karaoğlu N. Tıp eğitiminde rol modellik ve aile hekimliği için önemi. Turkish Journal of Family Medicine and Primary Care, 2012;6(2):30-35.

2. Başak O. Bir disiplin olarak aile hekimliğinin ülkemizdeki gelişim özellikleri. Turk Aile Hek Derg 2013;17(1):29-36.

3. Tıpta Uzmanlık Kurulu. Sözleşmeli aile hekimlerine verilecek aile hekimliği uzmanlık eğitimine ait tıpta uzmanlık kurulunca belirlenen esaslar. Erişim adresi: http://www.tuk.saglik.gov.tr/pdfdosyalar/ka rarlar/karar_406_degisik.pdf Erişim tarihi:19.09.2016

4. Türkiye Aile Hekimleri Uzmanlık Derneği. Aile hekimliği akademisyenlerinden Bakanlığa rest: Kadro talebinde bulunmayacağı! Erişim adresi: http://www.medimagazin.com.tr/anasayfa/guncel/tr-aile-hekimligiakademisyenlerinden-bakanliga-rest-kadrotalebinde-bulunmayacagiz-1-11-55820.html Erişim tarihi: 19.09.2016

5. Türkiye Halk Sağlığı Kurumu. Sözleşmeli aile hekimliği uzmanlığı 2014 sonbahar dönemi yerleştirme ilanı. Erişim adresi: http://www.medimagazin.com.tr/anasayfa/guncel/tr-sozlesmeli-aile-hekimligiuzmanligi-2014-sonbahar-donemiyerlestirme-ilani-1-11-63416.html Erişim tarihi:20.09.2016

6. Türkiye Halk Sağlığı Kurumu. Sözleşmeli aile hekimlerine verilecek aile hekimliği uzmanlık eğitimi 2014 ilkbahar dönemi başvuru ve yerleştirme işlmleri usul ve esasları. Erişim adresi: http://www.thsk.gov.tr/dosya/birimler/ah_e gitim_gelis_db/duyurular/sahu_2014_ilkba har.pdf Erişim tarihi:06.02.2017

7. Türkiye Halk Sağlığı Kurumu. Sözleşmeli aile hekimlerine verilecek aile hekimliği uzmanlık eğitimi 2015 ilkbahar dönemi başvuru ve yerleştirme işlmleri usul ve esasları. Erişim adresi: http://www.saglikaktuel.com/d/file/1331a8 82b4d740febc9260029fle3bbf.pdf Erişim Tarihi:06.02.2077

8. Türkiye Halk Sağlığı Kurumu. 2015 yılı sonbahar dönemi sözleşmeli aile hekimliği uzmanlık eğitimi yerleştirme sonuç listesi. Erişim adresi: http://www.thsk.gov.tr/dosya/birimler/ah_e gitim_gelis_db/duyurular/sahu_2015_kura/ sahu_2015_yerlestirme_sonuclari.pdf Erișim tarihi:06.02.2077

9. Türkiye Halk Sağlığı Kurumu. Sözleşmeli aile hekimlerine verilecek aile hekimliği uzmanlık eğitimi 2016 ilkbahar dönemi başvuru ve yerleştirme işlmleri usul ve esasları. Erişim adresi: http://www.thsk.gov.tr/dosya/birimler/ah_e gitim_gelis_db/duyurular/2016_kbahar_Dn emi_SAHU_Yerletirme_Usul_Esaslar.pdf Erişim tarihi:06.02.2017

10. Türkiye Halk Sağlı̆̆ı Kurumu. Sözleşmeli aile hekimlerine verilecek aile hekimliği uzmanlık eğitimi 2016 sonbahar dönemi başvuru ve yerleştirme işlmleri usul ve esasları. Erişim adresi: http://www.thsk.gov.tr/dosya/birimler/ah_e gitim_gelis_db/duyurular/Sahu_2016_Sonb ahar_Donemi_Basvuru_ve_Yerlestirme_Us ul_Esaslar.pdf Erişim tarihi:06.02.2017 